\title{
Destinos que no tienen pruebas: Pedagogías conjeturales, gestos inevaluables, errancias incorregibles, arte de la (actitud) crítica
}

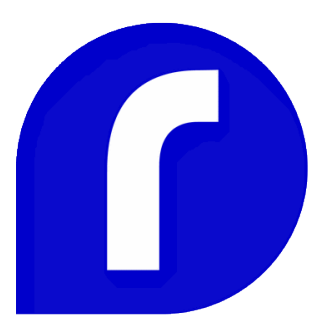

Recibido: 11 de mayo de 2020 Revisado: 8 de agosto de 2020 Aprobado: 14 de agosto de 2020

Facundo Giuliano Argentino. Doctor por la Facultad de Filosofía y Letras de la Universidad de Buenos Aires (Argentina). Trabaja para el Consejo Nacional de Investigaciones Científicas y Técnicas (Argentina) con el proyecto "Crítica de la razón evaluadora: implicancias ético políticas en educación" y también dirige, en la Facultad de Filosofías y Letras (UBA), el proyecto de investigación FilocyT "Educación, filosofía y psicoanálisis: la potencia de un anudamiento indisciplinario frente al capitalismo contemporáneo" con sede en el Instituto de Investigaciones en Ciencias de la Educación. Correo electrónico: giulianofacundo@gmail.com

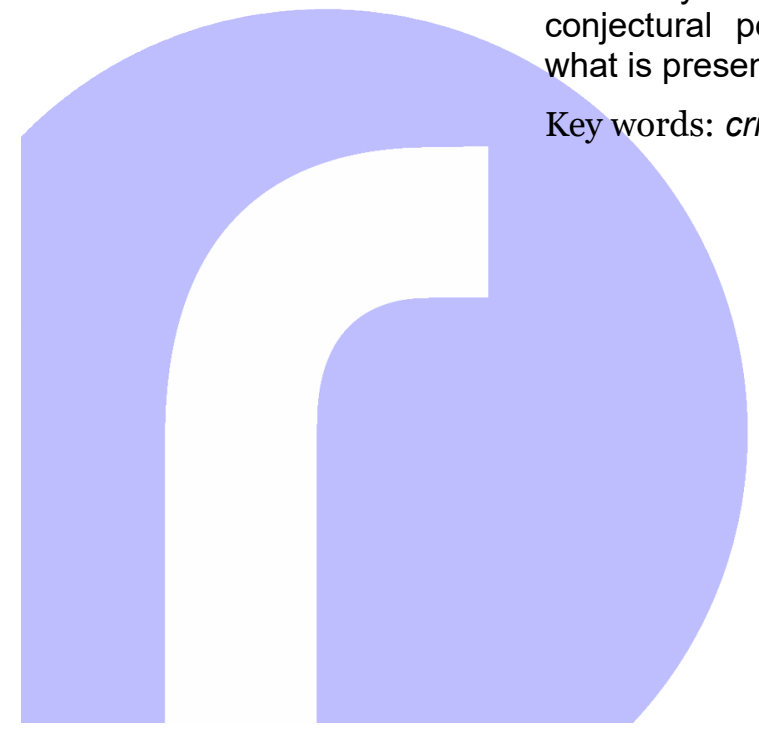

https://revistas.uned.ac.cr/index.php/rupturas cc) (i) (2)
Resumen: El presente ensayo convida diferentes interrogantes abiertos que conversan en forma in-conclusiva con los hallazgos pedagógicos-literarios correspondientes al final de la primera etapa de una investigación filosóficaeducativa más amplia que lleva por título "crítica de la razón evaluadora". En este sentido, aquí se presentan algunos de los principales movimientos éticopolíticos que hemos encontrado para hacer frente al furor de la razón evaluadora que acecha nuestro tiempo. De este modo, se busca interpelar a la educación contemporánea para que no atrapada en la sinonimia instalada por la modernidad/colonialidad que hace de ella una mera excusa para evaluar. Frente a esto, se esbozan las pedagogías conjeturales, las gestualidades in-evaluables, las errancias incorregibles y lo que aquí se plantea como arte de la (actitud) crítica.

Palabras clave: crítica; literatura; filosofía; educación; razón evaluadora

\section{Destinations that have no Proof: Conjectural Pedagogies, un- Evaluable Gestures, Incorregible Mistakes, Art of Critique (Attitude)}

Abstract: This essay invites different open questions that converse in an inconclusive way with the pedagogical-literary findings corresponding to the end of the first stage of a broader philosophical-educational investigation entitled "Critique of evaluative reason". In this sense, here are some of the main ethical-political movements that we have found to face the rage of evaluative reason that haunts our time. In this way, the aim is to challenge contemporary education so that it is not caught in the synonymy installed by modernity/coloniality that makes it a mere excuse to evaluate. Faced with this, conjectural pedagogies, un-evaluable gestures, incorrigible mistakes and what is presented here as the art of critical (attitude) are outlined.

Key words: critique; litterature; philosophy; education; evaluative reason 


\author{
A manera de introducción: andar por la sombra y (no) estar a la \\ sombra de...
}

1. En un texto de comienzos del 2000, Horacio González $(2018,220)$ percibe que la institución educativa que conocemos con el nombre de "facultad" está eclipsada por la red de exámenes parciales y finales que les quita a estudiantes todo lo interesante que son al comienzo para, progresivamente, victimizarlos con el sistema de parciales y terminar "masacrados al final por el peso enorme que tiene la lengua del examen".
Buscando la tesitura de una fiesta que no llega, se presiente por la altura una diosa que nos pega al juzgar la criatura. Borra el pájaro el borrón

y se acerca de rondón a un montón de breve sombra.

Si es lo que no te nombra es la estrella que se escombra. José Lezama Lima, Lo que no te nombra.

En una de las gestualidades retóricas que utilizaba mi bisabuelo para despedirse de mí con enigmática picardía, luego de alguna visita, había una que solía repetir con especial énfasis y una traviesa sonrisa: "Anda por la sombra...". Es curioso; no decía "Cuídate del sol", "Mira la calle al cruzar" o "No te metas en problemas", sino que recomendaba andar por la sombra como si allí anidara, además de la chance de no 'insolarse' (con todos los sentidos que esta palabra puede guardar en una época que ostenta luminosidad), una aventura misteriosa, un consejo de sabio o, simplemente, esa andanza arcana que los campesinos solían cultivar incluso en su inquieta y laburante vejez. De cualquier modo, resulta tentador meter mano y revolver en ese bolsón semántico por encontrar contrasentidos a un tiempo jactancioso de excesiva luz, de "nuevos" iluminismos, de proliferación de pantallas que parecieran despojar de sombra (y de enigma) a los rostros. Se llamaba Dionisio, un nombre que también guarda algo que todavía puede ser evocado: inspirar la locura como forma de liberación del ser normal, algo que se permitía entre el cultivo de la agricultura y las escenificaciones de un rudo conocedor del suelo húmedo pampeano. Su sintagma lo completaba un sinónimo del recibir sin condición: Ospital (un lugar que encierra la locura, aunque no deje de inspirarla).

En un sentido bastante diferente, casi antagónico podría decirse, podemos encontrar la expresión "a la sombra de..." en un texto que solo parece haber circulado en una versión que se subtitula "preliminar y descartable" y se firma en abril de 2011 con un aviso de posible pertinencia para tres años más tarde (el periodo que suele tardar en repetirse la prueba estandarizada de la OCDE). Se trata de un ensayo literario e inédito acerca de la evaluación que Graciela Frigerio titula "A la sombra de PISA". El título podría operar como una suerte de dedicatoria, pero refiere a lo que queda eclipsado ${ }^{1}$, disminuido, 
sub-alternizado, a ese código que en ciertos países implica cumplir una condena y pasarse un tiempo, "a la sombra", en prisión. Se trata de la sombra como acumulación impalpable de culpas que siguen a los pasos, por un lado, por delante y por detrás, y donde una insistencia se avista, sin embargo, aun así, de todos modos. Alimentada de la pulsión de muerte y su tendencia a homogeneizar el mundo bajo el manto fantasmal de lo Uno, la fiebre evaluativa -que percibe Frigerio- es el fondo sobre el que se desdibuja la figura docente.

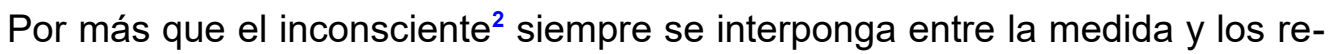
sultados, las nociones que hacen a las puntas que coronan la razón evaluadora tienen sus constantes históricas y sus variantes de mercado: mérito, voluntad, esfuerzos, inteligencias desiguales (o múltiples), resiliencia, y un largo etcétera. Mientras, la sombra que ningunea crece: ya no importa la relación con el saber ni los saberes de la relación, tan solo lo pasible y lo posible de comparar (o de comprar, me dicta un fallido de mis manos). Su fuerza proviene de la debilidad de los demás; es fuerte solo "en comparación" y así establece su criterio de autoridad (y veracidad) que otorga eficacia al dispositivo cubierto con el escudo inmunitario de lo incuestionable. De ahí que sepa muy bien qué es el aprendizaje y cómo provocarlo: "Al borde de un precipicio, cabeza abajo, agarrado solamente por los pies por su más ilustre profesor, es así como el aprendiz repite, asustado, la lección de la mañana" (Tavares 2018, 181). Y así también se hacen fuertes los censores, que también pueden ser máquinas (abusivas, delirantes, policiales) porque nunca tendrán ojos húmedos, pero también las herejías que se tejen en las invisibilidades estratégicas.

Frigerio tampoco olvida a militantes, activistas y amantes de las competencias y las performances que se regodean en los entrenamientos de preparación para las pruebas, aun al costo de descuidar la enseñanza, pues lo privilegiado siempre es "salir bien notado". Pero eso de "salir" es algo engañoso, ya que allí donde está el cartel de "Salida", en realidad, se esconde una entrada infinita al mundo del rendimiento que instala el pernicioso deseo de "estar a la altura" o seguir escalando (compitiendo con otros) y obteniendo cada vez mejores promedios. Es cierto que "los veredictos de la prueba" producen tiempos de goce para los "narcisismos exaltados" (Frigerio 2011, 13) que viven de una dieta a base de "ser los mejores", "subir en la escala comparativa", habitar el "cuadro de honor", "hacer podio", "ser más que los demás" y un sinfín de maneras de engordar el yo. Imbuidos en la lógica del mérito, la nerviosidad nos consume al punto que se desea la aprobación como única forma de vencerla en apariencia y por un rato. Cioran $(2015,94-96)$ ve en esto el deseo desesperado de un engaño y clava una seguidilla de interpelaciones al ángulo: “¿por qué extenuarse para ser alguien? ¿Por qué extenuarse incluso para ser? (...) ¿Hay algo más funesto (...) que una acumulación de méritos?".

Frigerio $(2011,16)$ también indica cómo en educación, de la mano de la pedagogía, la evaluación -y las formas que tomó- produjo efectos en las biografías afectando a los sujetos mucho más allá de lo que (la inteligibilidad de) las

\author{
2. Frigerio (2011) realiza una \\ filosa observación al Lacan de \\ los Otros escritos que llega \\ afirmar al inconsciente como \\ "un saber que no piensa, no \\ calcula, no juzga" descuidando \\ así que las tópicas del aparato \\ psíquico ponen en evidencia el \\ modo en que el juicio cobra \\ cuerpo de superyó, ideal del \\ yo, yo ideal.
}


escalas de calificación instaban a comprender, perturbando las percepciones de sí y de los otros, las relaciones pedagógicas y sociales, hasta llegar a oficiar de "documento de identidad" que permite (o no) franquear las fronteras de instituciones que están atentas a resultados, promedios, performances. Así entraron (y continúan entrando) a escena los procedimientos que ostentan objetividad, que declaran neutralidad y fingen inocencia. Algo que quizá ya alertaba la percepción filosófica de Cioran $(2015,9)$ en su época: "Examinarse a sí mismo ya es algo malo; examinar a la especie (...) es aún peor: es atribuir fundamento objetivo y justificación filosófica a las miserias arbitrarias de la introspección".

Tal vez haya sido uno de los éxitos del desarrollismo y el neoliberalismo la instalación de la evaluación como rejilla previa y posterior que ha de aplicarse a toda política que, pretensión de eficacia y eficiencia mediante, deba proporcionar resultados acordes a la lógica de la exigencia. Como observa Frigerio (2011, 17-19), esa exigencia ha ido tomando cada vez con más fuerza la forma de "una pasión por el buen número, el mejor porcentaje, la más exacta expresión estadística, el más exquisito análisis cuantitativo", todo lo cual perfila una cuantofrenia que busca complementarse con análisis cualitativos y satisfacer su pretensión universal auto-investida "(y luego investida por los discursos que sobre ella se yerguen) como unidad de medida" que exige prescripciones curriculares evaluables/medibles, relaciones institucionales "apropiadas a los fines de la notación buscada", procedimientos didácticos "aptos a producir el hacer medible", una educación cimentada sobre la primacía de una economía de la competencia y de las acciones "gananciales" (con su inevitable costado de pérdidas, daños colaterales y "debilidades" concebidas como obstáculos o amenazas). En otras palabras, es lo que Carlos Skliar $(2003,61)$ refiere con la imagen del mundo reducida a cantidades manipulables y obscenas que, por más impresionantes y rimbombantes, inquietante y reales que sean "no habría que dejarse gobernar por ellas o, lo que es mejor decir, no habría que dejarse arrastrar por esa mismidad que todo lo cuenta, en sumas y restas trazadas desde una alcantarilla, olvidando al sujeto que queda sumergido o ignorado entre posiciones numéricas, coeficientes, pérdidas y ganancias y umbrales" porque si no cualquiera se reduce a su manipulación numérica, a su medición, a su cuantificación y se queda sin rostro, sin lengua, sin cuerpo o con un rostro, una lengua y un cuerpo debidamente mensurados.

En este marco, Jorge Alemán acierta cuando sostiene que "la matriz de socialización del capitalismo es la evaluación" porque el capitalismo se caracteriza efectivamente por producir un tipo de subjetividad que:

tiene que concebirse a sí misma como valor, como en competencia consigo misma, en una relación empresarial consigo (...) y de un modo tal que esté todo el tiempo en juego su máximo rendimiento $\mathrm{y}$, por lo tanto, un rendi- 
miento que está lógicamente, para decirlo en términos

psicoanalíticos, "más allá del principio de placer" (en Giuliano 2018, 31).

Un rendimiento que durante determinada temporalidad tiene que automaximizarse, auto-valorizarse, de manera ilimitada y en un "movimiento circular donde la subjetividad tendencialmente se vuelve capital y el capital se vuelve tendencialmente subjetividad" (Alemán en Giuliano 2018, 32). Así funciona el círculo vicioso de la evaluación, cuyos problemas pretenden ser resueltos incluso con más evaluación, lo que podría recordarnos cierta evocación de la guerra:

Todos querían que la guerra terminara (...) pero nadie sabía cómo hacer para ponerle fin. Lo demoníaco (...) es que todos empezamos a comprender que las armas que usábamos eran tan mortíferas que ninguno de nosotros estaba preparado para soportarlas. Y las armas por sí mismas no iban a detener la matanza (Piglia 2015, 80).

Como si la conductista 'máquina de enseñar' hubiese triunfado y la docencia reflexiva hubiese pasado de la aspiración a una estancia en la torre de marfil a una permanencia en una torre de control, la formación para la competencia parece dejar cualquier atisbo formativo de convivialidad. Illich y Raúl FornetBetancourt son partidarios de la convivialidad, como forma de crear comunidad de pensamiento mutuo y común y "hacer de los espacios educativos espacios de resonancia de saberes" (en Giuliano 2017, 209), así como -al decir de Ignacio Ellacuría- ante una política que a coro grita “ ¡A sus órdenes mi Capital!", la educación se torna una chance de "romper ese cautiverio comprometiéndose también en la lucha por liberar la política" (Fornet-Betancourt en Giuliano 2017, 206). En este sentido, podría evocarse a Glissant (2019) cuando invita a pensar la política desde las poéticas que no cesan de combatir y en su detalle no habita un punto de referencia descriptivo, sino una extensión no medible: un revelado donde lo político aloja la potencia de un gesto injuzgable.

Muy en contraposición de Jean-Luc Nancy (2009) que encuentra en el gesto evaluador un sentido afirmativo de la evaluación que hace de la política una forma de distinción que crearía valor y al cual se ataría la existencia, dejando lo incalculable (es decir, lo no intercambiable, lo no mensurable ni equivalente) como aquello que excede a la política (y no como su parte constitutiva) al mismo tiempo que esta solo debería hacer posible su existencia, mantener su apertura, asegurar sus condiciones de acceso, pero no adoptar su tenor. De modo que se priva de lo incalculable a la política; es decir, se la priva del arte, del amor, de la amistad, del pensamiento o el afecto, al tiempo que a es- 
tas variantes de lo incalculable se les priva de su propia política, ya que "EI elemento en el cual lo incalculable puede compartirse lleva por nombre arte o amor, amistad o pensamiento, saber o emoción, pero no política" (Nancy 2009, 34).

\title{
Gestualidades inevaluables y pedagogías conjeturales
}

\author{
No olvides \\ que fuimos hechos a la vez \\ de bestialidad y viudez \\ de lágrima y consuelo \\ de vísceras de espantos de pliegues. \\ Y que un gesto tuyo mío nuestro cualquiera \\ puede rehacer el mundo \\ o incluso \\ acabar por deshacerlo. \\ Carlos Skliar, Hilos después.
}

Un aviso, con su habitual carácter de premura, se esconde en un libro de 1931 y parece todavía contener cierta vigencia:

Se necesita un maestro. Sí; pero uno de los nuestros, a quien escuchar, de los que hayan sufrido los mismos quebrantos, los mismos abatimientos, las postergaciones sin límites. Maestros, no fonógrafos repetidores de dogmas, de mitos, de teorías. Uno de los nuestros, listo de comprensión e indulgencia. Uno de los nuestros mejor que nosotros, se necesita (Scalabrini Ortíz 1933, 142-143).

Quien conozca el texto, recordará que el aviso culmina con la recomendación a Macedonio Fernández de que se presente. Pues, para Scalabrini, Macedonio encarna esa figura docente en plural "mejor que nosotros", pero que no deja de ser "uno de los nuestros" y, quizá por esa conjunción compartida de padecimientos y sensibilidades, se lo necesita. Al ubicar el aviso en un libro y no en un periódico, no se trata de una acción que media un fin ni de una acción que tiene un fin en sí misma; se trata de un mero gesto.

Algo similar también podría decirse de Ezequiel Martínez Estrada cuando, en 1959, pronuncia un importante discurso a la juventud en la Universidad $\mathrm{Na}$ cional del Sur. Allí cuestiona cómo no se enseña a venerar mártires, sino a celebrar triunfadores; cómo se inculcan "las doctrinas norteamericanas y so- 
viéticas del éxito y del deporte, del progreso mecánico y de la praxis idolatrada en la técnica" (Martínez Estrada 2013, 72). Se inclina así por los rumbos y combate los planos de turismo cuyo único destino es el cambio de servidumbre que hace que la juventud busque influencers y no maestros, que busque técnicos y no arquitectos de ideas o músicas, que busque escribas y fariseos y no defensores de los esclavos negros (como el capitán Brown que inspiró y guio desde otro tiempo a Thoreau y este guio e inspiró desde otro tiempo a Martínez Estrada y este sigue inspirando cuando hasta en sus últimos gestos guarda una orientación subversiva: a quienes digan que nunca entrarán en nuestras aulas y conversaciones, replicar que nunca entraremos en sus ferreterías).

¿Podría decirse lo mismo de Borges y su animadversión contra los exámenes? Hay quienes dicen que directamente no los tomaba; otros dicen que sí hubo exámenes; pero jamás formuló una pregunta en ellos e invitaba a estudiantes a elegir y considerar un aspecto cualquiera de un tema en el que ni por remota casualidad exigiría una fecha ya que ni él mismo las recordaba. Por medio de estas incógnitas, o mitificaciones, Horacio González (2019) percibe que lo que late insinuado detrás ellas es una revolución pedagógica y la esboza con el nombre de pedagogías conjeturales. Ellas tendrían un basamento irónico que arroja precisas demoliciones (con un "belicoso placer") a un problema, que expresa un deseo de conocimiento, y que encuentra su cauce "a la sombra de su imposibilidad" (González 2019, 152). Así se delinea una forma de problematización que, cual músculo que puede darse el lujo de pasar por bobo, tiene la generosidad constante de dar un ritmo, de bombear vitalidad y acompañar la oxigenación de las pedagogías conjeturales: se trata de la disputa, "no entendida con la idea oficial de que de ella sale una 'enriquecida síntesis', sino como armazones pedagógicos que tienen menos respaldo -son conjeturales porque la realidad también lo es-, que el que le prestaría la presente búsqueda de una verdad" (González 2019, 165).

Lo cual se acompaña también de una idea bufonesca del conocimiento como una "forma de intentar presentarse en nombre de otras piezas del conocimiento, piezas necesariamente incompletas, nunca terminadas, piezas humorísticas" (González 2018, 215) porque en ello quizá radique la principal chance de que pueda darse otro conocimiento hecho de piezas sueltas y promesas que la "sociedad del conocimiento", así como la "sociedad del aprendizaje" y "de la información", generalmente inhiben y destruyen. Pues el conocimiento, o el aprendizaje, como información, reduce ese "conjunto de hechos contradictorios e inaprensibles por los sistemas normales de acumulación y progresión de explicaciones" que es la vida; y, cuando eso ocurre, "cada sujeto quedó expropiado en su calidad de único depositario de sus enigmas y reservas, para ser transformado en papilla descifrada" (González 2004, 344) destinada a alimentar los sistemas de control y fiscalización. Por eso quizá, en una línea similar, Agamben $(2018,158)$ sostiene que "a cada ser humano se le ha entregado un secreto y la vida de cada uno es el misterio que pone en escena este arcano" y que "no desaparece con el tiempo, sino que se vuelve cada vez más intenso" hasta mostrarse como un gesto 
que, en tanto misterio irrevelable e in-inscribible en los dispositivos de los medios y los fines, "es injuzgable".

González $(2018,109)$ se rebela contra el ethos burocrático que apresa las instituciones educativas con un "Canon de Tasación" que expresa un idioma complejo e incluye "un pensamiento registrador, arancelario e incentivatorio". Dicho canon obliga a docentes al "referismo" o "referatismo" (algunos ismos provenientes de la figura exacerbada del réferi), a cumplir actividades de contaduría y expulsar el drama de la contingencia, en suma, a convertirse en evaluadores y evaluados insertos en una esfera de enjuiciamiento que desencadena incesantemente escenas de juicio final. Al mismo tiempo, se siembran las sospechas de que no es posible una existencia sin juicio, pero ellas no alcanzan a inhibir "la formulación de la utopía general del acabamiento del juicio" (González 2018, 114). De lo contrario, la razón evaluadora se apoderaría de las instituciones en tanto posibilidad de volverlas inquisiciones; es decir, "instrumentos de categorización, enjuiciamiento y aprobación de credenciales que en su extremo delirante implica persecución de la vida intelectual" o "una pregunta persecutoria, un inquirir inquisitorial, que fusiona las ideas de Pregunta y Tribunal", lo que no es más que una cacería "en nombre del ideal pedagógico de la adaptación" (González 2018, 115-116). De ahí el combate contra el inquirir inquisitorial que fusiona las ideas de pregunta y tribunal, un combate librado en esas grietas del espacio y del tiempo que suelen ser las aulas cuando estas se dedican al enigmático arte de transmitir alguna enseñanza.

Y es que, para mala noticia de los profetas del odio (quienes gustan de proliferar diretes decadentes en torno a imposibles y utopías), hay docencias desprejuiciadas (o desjuiciadas) que no aplazan y desmontan el "progreso" del entender dándole lugar a la bola sin manija que va de un lado a otro no declamando lo imposible ni reclamándolo, sino, tímidamente, haciéndolo. En palabras de un estudiante de González, se alza vivo y coleando el testimonio de una docencia conjetural capaz de burlar y fracturar la razón evaluadora:

Tomó exámenes en el colectivo 12 (Puente PacíficoConstitución). Organizó caminatas a la peatonal Lavalle para advertir de la superposición entre Todo x $\$ 2$ y cines antológicos o aceptó monografías dadaístas que incluían cien páginas totalmente en blanco -esta última ocurrencia proviene de alumnas que habían pescado su predisposición realmente desprejuiciada. Nunca "bochó" a ningún alumno porque siempre consideró que había algo de su rol que no tenía derecho a violentar a alguien mandándolo a rehacer nada. La escritura y la lectura están ahí no 
para ser juzgadas sino para que se vuelquen en todo lo que fuimos hasta el momento de toparnos con ellas y poder seguir pensando, cuando no pensarlo todo de nuevo. Nadie sabe más. Porque entender, para González, es un momento no en una curva de progreso sino en una conciencia que tiene el aspecto de una bola sin manija. Alguna vez reivindicó el "leer mal" como una forma crítica de leer. (...) Porque en las aulas nos enseña que las cosas siempre son difíciles pero los más difíciles somos siempre nosotros. No estar a la altura de uno mismo es una constante y un desafío de redención en el día a día (Laxagueborde 2018, 12-14).

Una huella imprescindible, constituida por una bataola de gestualidades ético-políticas e in-evaluables, en una época distópicamente kafkiana en la que cualquiera por el mero hecho de vivir puede resultar imputado o, si la acusación no ha sido formulada, puede llegar a no dudar en autoacusarse o autocalumniarse. Una evocación a lo conjetural de pedagogías que provocan esa tercera forma de la acción que "rompe la falsa alternativa entre el hacer que siempre es un medio respecto un fin (la producción) y la acción que tiene en sí misma su fin (la praxis)" (Agamben 2018, 160). Se traza así, sin querer queriendo, un gesto como el no-acto aparecido en el acto de abrir un espacio en el que "los dispositivos que conectan las acciones humanas como fines y medios, imputación y culpa, mérito y demérito, se vuelven inoperosos" (Agamben 2018, 162).

No se trata de idolatrías, ni de paradigmas, ni de "casos especiales", ni de singulares deidades, ni de una "comunión de los santos" -como solía aborrecer David Viñas-. Tan solo de unas pedagogías que, en su estado inmanente de conjeturalidad, guardan una sublime generosidad. Son tan silvestres que por ahí andan entretejiendo huellas, entre el pasado y el presente, en los bosques públicos de la formación y en las vidas que las hacen carne de conversación. Incluso podríamos encontrar en un joven Ricardo Piglia (2015, 148) otro precursor de las pedagogías conjeturales cuando, en su diario de 1964, escribe que "lo que se puede enseñar es tan limitado que alcanzaría con una frase de diez palabras. El resto es pura oscuridad, tanteos en un pasillo en la noche". Seguiremos tanteando, entonces, en los recovecos de los días más opacos. Tal vez por todo lo que implica esa aventura, la enseñanza es la brevedad de un comienzo que se pierde en la trama y el resto es la búsqueda de esa infancia. 


\title{
Incorregibles (poéticas del traspié entre el errar, el fracasar o el equivocar)
}

\author{
Las faltas no tienen límites \\ como tienen los terrenos, \\ se encuentran en los más buenos, \\ y es justo que les prevenga: \\ aquél que defetos tenga \\ disimule los agenos. \\ José Hernández (2009, 261).
}

La palabra 'incorregible' suele invocar el espíritu de aquella sentencia borgeana dirigida a las singularidades peronistas que constituyen el pueblo argentino, sentencia precedida de una advertencia "no son ni buenos ni malos" y que desemboca en la recordada conclusión "son incorregibles". Interesantes sentidos se disparan de esa pieza histórica si recordamos que el "individuo a corregir" es una de las 'figuras de anormalidad' que Michel Foucault (2000) toma en su célebre curso de 1975 conocido bajo el título de Los anormales. Siguiendo esta huella, Carlos Skliar $(2003,140)$ encuentra que el 'individuo a corregir' es el individuo incorregible que, en tanto tal, será intervenido específicamente por tecnologías "de la corrección, de la recuperación y, en síntesis, de la normalización", lo que no hace más que darle cause a esa maña de seguir preceptos inculpadores y corregir lo visualizado como "falta" (ya sean errores, "desvíos", desorientaciones o traspiés).

Así no se hace difícil entender cómo es que, en el imaginario social, el error suele aparecer asociado a la vergüenza, la estupidez, la ignorancia, la degeneración, o alguna psicopatologización de moda relacionada a la desatención, la distracción, la falta de interés, la timidez o "falta de preparación", el desequilibrio emocional y un largo etcétera. Tal vez este panorama esté reforzado por una enseñanza falsamente montada sobre el acierto, donde sus propias equivocaciones intentan ocultarse y sus errores permanecen velados $\mathrm{o}$, a lo sumo, lo más disimulados que se pueda. Aquí puede que opere la histórica asociación moral del error con el mal y de lo correcto con "lo recto", pero ¿qué es lo que hace una equivocación imposible de recordar o imposible de olvidar?

Se sabe que mil doscientos años antes que René Descartes escribiera su famosa sentencia "cogito ergo sum", Agustín de Hipona escribió "fallor ergo sum", no solo dejando entrever relaciones fundamentales entre errar y existir, también dando a pensar que el hecho de estar vivo se alimenta del malentendido y una dieta con base en equivocaciones. Como diría Kathryn Schulz $(2015,31)$, el error "como un rasgo de nuestro paisaje interior (...) es el colmo del cómplice que actúa desde dentro". No obstante, coincidimos con Schulz (2015) en que el error surge de la innegable brecha entre el interior y el exterior, entre lo singular y lo general, entre las palabras y las cosas, entre 
lo presente y lo primigenio, lo cual da la pista de que también es la grieta por donde entran las luces (y las sombras) de la imaginación, de la invención y de la esperanza. Se trata del yerro como un don, como una fuente inagotable (e irremplazable) de humor y de arte.

De hecho, para fortuna de las paradojas, Phillip Roth, en aquella novela con la que gana el Premio Pulitzer de Ficción en 1998 (Pastoral americana), sostiene que de lo que se trata la vida no es de entender bien al prójimo, sino de malentenderlo una y otra vez para, luego de una cuidadosa reflexión, malentenderlo de nuevo. Otra manera de insistir y persistir en la equivocación como signo principal del vivir. O como signo del goce, si recordamos a Oscar Wilde (2004) cuando sostiene el secreto de la vida como el placer de estar terriblemente equivocado. O como si una interdependencia constitutiva entre el error y la comedia se entretejiera en la risa por la pifiada ajena (que funciona como espejo en el que, sin darnos cuenta, miramos nuestra propia errancia).

Si llevamos el asunto a un terreno más escabroso, ya que nunca faltan moralinas de la perfección dedicadas a refutar posiciones filosófico-literarias con planteos de pose oligárquica y tributo al campo médico, podríamos decir que (aunque no los prefiramos, y causen tanta gracia como morbo) los errores médicos se erigen, en los países "desarrollados", como una de las causas de muerte más altas, ocupando una cómoda posición, por delante del cáncer de mama y el sida, en el top 10 de la muerte. Fuera de broma, a quien le interese el morbo de las cifras puede consultar la documentación utilizada por Schulz $(2015,278)$ o hacerse una idea con una analogía por ella ofrecida: "Para que la aviación comercial tuviese el mismo número de víctimas en Estados Unidos, tendría que estrellarse cada tres días un 747 lleno matando a todos cuantos estuviesen a bordo". La cuestión es la capacidad desarrollada en el campo médico para ocultar, negar o minimizar la pifiada cotidiana y cómo la equivocación atraviesa una metamorfosis que termina por aparecer como "complicación", o "resultado imprevisto", o "efecto secundario". Sin desatender la histórica influencia que el poder médico, en complicidad con el mercado, ejerce sobre la sociedad, ¿serán de esos procedimientos c(l)ínicos para ocultar el error que viene alimentándose subrepticiamente la tendencia a no hablar del fracaso y que en escena solo quede el éxito como única actuación posible?

Como si el hecho de fracasar ya supusiera un efecto ontológico que sentencia a portar su adjetivación, su mote, su carga junto al nombre propio; y de por vida. Una cadena perpetua que desoye completamente la idea nietzscheana de que hay fracasos, pero jamás fracasados ni fracasadas. Como si por el mero hecho de existir se estuviese condenado al éxito y no hubiera margen de error; un destino que solo podría ser torcido por una educación que pueda liberarse de ese yugo y plantearse que, como expresa Skliar (2011, 167), "educar también puede ser asumir la posición de ser fervientes devotos del fracaso". Pues, en el espacio-tiempo educativo puede alentarse fracasar tan solo por pensar en nuevos, magníficos y conmovedores fracasos 
que permitan seguir pensando. Como si fracasar permitiera ir disimuladamente por la vida, mientras que a "ser exitoso" no se llega sin humillar y ser humillado, sin matar y ser matado, sin evitar todo el tiempo nuestra fragilidad constitutiva.

$Y$ es que ¿hay acaso otra cosa que el fracaso? ¿No se fracasa, por ejemplo, en el combate cuerpo a cuerpo con la muerte? ¿En la búsqueda infructuosa de un amor que nunca llega a tiempo? ¿En la desesperada y torpe asimilación del saber? ¿En la cruel pérdida de la memoria de la infancia? (...) Aunque algunos insisten en decir que del fracaso algo se aprende. Lo que se aprende del fracaso no es nunca lo que queremos aprender. (...) Porque, al fin y al cabo: ¿qué otra cosa podemos hacer sino fracasar una y otra vez? (Skliar 2011, 168).

Algo similar podría decirse de la palabra 'equivocar'. Como si su mera pronunciación sonara a una infeliz coincidencia con la vida misma, pero también a ese camino, a esa dirección o a ese sentido que se ha perdido en la andanza y suspende el juicio. Porque si hasta algún aristócrata se ha percatado de que hay mucha queja sobre la fragilidad de la memoria y muy poca sobre el sano juicio, no sorprendería el testimonio del pensador ilustrado que ha encontrado más verdad en un sordomudo que en esos filósofos del juicio que, para el "buen entendimiento", siempre reclaman un órgano faltante. Es lo que, en otro tiempo, vio -y vivió- Skliar (2011) cuando descubrió cómo opera la evaluación en la educación de los sordos: clasificaciones basadas en baterías de test derivadas de la lectura de tal o cual psicólogo del momento (ediciones inglesas o francesas, traducciones castellanas) que fácilmente le llevarían a la conclusión de que un grupo numeroso de niños sordos -independientemente de diferencias de edad, género, clase social y nivel de escolaridad, etc.- realizaban agrupamiento de objetos exclusivamente por "identidad perceptual" sin cambiar sus criterios conceptuales, sin abstraer, sin generalizar; en síntesis, sin pensar. Si no fuera por un pequeño gesto, a contracorriente de todo lo que le habían dado en su formación como indiscutible (como, por ejemplo, que 'hacer gestos' en educación de sordos era incorrecto), nunca podría haberse enterado de que se trataba de una gestualidad de igualdad la que le llevaría a cambiar la impunidad de la sentencia por el dolor de aquella ignorancia sobre la que desearía haber escrito: "todos los niños sordos por mí evaluados demuestran ser notablemente receptivos a la primitiva comunicación del evaluador" (Skliar 2011, 138). La anécdota se complementa con el hallazgo de una lectura en la que un investigador documenta la literatura colonialista europea de los siglos XVI a XVIII y sistematiza la des- 
cripción que los autores de la época hacían de los nativos africanos, cuya correspondencia descriptiva entre los textos coloniales y los de la psicología de la sordera resulta absoluta (e incluso se halla el mismo paternalismo, el mismo etnocentrismo), lo que lleva a Skliar $(2011,139)$ a una enseñanza que se graba a fuego: jamás "tiene que ver con lo visto,; tiene que ver con la posición de quien ve".

Hay juegos de lengua(je) que le dan al fallido un lugar fundamental, una fuente de sentidos por explorar, una cuna de esperanzas, suposiciones y acontecimientos contra-factuales. Sillares lingüísticos donde pueden tomar asiento las insinuaciones, las sugerencias, las generalizaciones y las matizaciones. Por eso, quizá, tal vez, probablemente, Schulz (2015) lamenta que en la lengua inglesa el subjuntivo esté desapareciendo casi por completo y solo se conserve en sutilezas gramaticales.

Como también hay en la escritura un grado inevitable de entendimiento erróneo, una verdad en fuga que, en el momento preciso que parece captarse (por no decir capturarse), titila, se distorsiona y se escapa zigzagueando. Pero cuando no se busca su captación (su captura) y se habita el sobresalto, la inquietud y el desafío, una errancia puede advenir poética. ¿Y será que puede haber poesía sin errancia? ¿Y qué traspié no aloja su poética de la tragedia y de la comedia en medio del drama humano? ¿O qué poética desea tanto la pulcritud como para presentarse limpia del barro (y del barrio) que le dio nacimiento? Ni siquiera el frío formalismo hace fenecer la fogosa intimidad que se insinúa entre el yerro y la poesía, entre el arte y el equívoco. Recordemos a ese arquitecto que devino una leyenda no precisamente por sus planos, sino por hacer del aparente dislate una actuación y de la actuación una enseñanza, y de la enseñanza una infancia incorregible, y de la infancia incorregible una vida artística abierta al mundo, Jorge Bonino:

Para demostrar la esencial inconsistencia del lenguaje, a veces, solía tener a mano una mesa que transformaba en escritorio colocando papeles, libros, lapiceros y otros útiles rigurosamente ordenados; luego le mostraba al público un cartel que decía "¿está prolijo?" Y el público gritaba al unísono "¡siii!". Después desordenaba completamente el escritorio y les mostraba un cartel que decía: "¿está improlijo?" y el coro asentía. Entonces tomaba el diccionario y leía las diferentes acepciones de la palabra prolijo y les informaba que improlijo no aparecía. Otras veces escribía en mi pizarra la palabra "murciégalo" al lado de "murciélago" y hacía votar a los presentes por la forma 
correcta, para entonces demostrarles que en el diccionario convivían amigablemente, y los amonestaba con severidad y gritaba "¡nebrijas!", y les advertía que tomaran precauciones antes de corregir a los niños cuando dicen vedera, mondiola, almóndiga o bayonesa... (en Casarín 2014, 73).

Palabras entramadas de incorregibles: errar, enseñar, escribir, poetizar. Una imposible conclusión: errarle al tiro una y otra vez para, luego de una cuidadosa reflexión, volver a errarle. A lo mejor salvamos a alguien, además de a nosotros mismos.

\title{
(Actitud) crítica y arte de no ser evaluado
}

\author{
El Negro disfrutó de una discreta \\ fama y sin embargo el culturoso \\ poder tiene con él-sino penoso- \\ una deuda que es pública y secreta. \\ Nunca vieron que sabía escribir. \\ Para una mirada acartonada, \\ cometió el error de hacer reír \\ $y$ de tener lectores a patadas. \\ Aviso a los curiosos por venir: \\ la crítica ha vivido equivocada. \\ Juan Sasturain, El versero.
}

Una relación íntima entre poesía y crítica se insinúa con mayor explicitación cuando leemos los trazos de Roberto Jorge Santoro $(2013,444)$, trazos cuya vitalidad no cesa (mal que les pese a los verdugos que promovieron su desaparición), donde pueden encontrarse definiciones criticas/poéticas como "Caída: el capitalismo / no mira por dónde camina", "Quiebra: al imperialismo / no le salen las cuentas", "Exactitud de la tardanza: los enemigos del pueblo / al final caen en la cuenta". Pero una vieja pregunta sigue apareciendo e insistiendo sin parecer nada obvia: ¿qué es la crítica?

En una conferencia dictada en 1978, en la Sociedad Francesa de Filosofía de la Universidad de la Sorbona, Foucault $(2018,45-56)$ se propone decir algunas palabras en respuesta a lo que considera un proyecto de inacabada formación, prolongación y renacimiento "en los confines de la filosofía, muy cerca de ella, muy en su contra, a sus expensas, en dirección a una filosofía por venir, acaso en lugar de toda filosofía posible". Sin sacar el pie de la "alta em- 
presa kantiana", Foucault $(2018,46)$ data a partir de los siglo XV y XVI, en el occidente moderno, pequeñas actividades que llevan el nombre de 'crítica' y se asocian a "cierta manera de pensar, de decir, también de actuar, cierta relación con lo que existe, con lo que se sabe, con lo que se hace, una relación con la sociedad, la cultura, (...) con los otros" y que llama actitud crítica. Así se perfila la "manera crítica" como una manera de pensar, de decir y de hacer que se ejerce siempre en relación con (lo que la dota de una heteronomía constitutiva) un juego de relaciones que le permite generar articulaciones bajo formas de ataque que son, a su vez, atacadas (lo cual le da un carácter ineludible de fragilidad).

Sin detenerse en el contexto geopolítico que marca los siglos XV y XVI como fundamentales para la empresa colonial y la expansión de Europa, Foucault $(2018,49)$ considera que una de las preguntas cardinales de lo sucedido en esos siglos fue ¿cómo gobernar?, la cual se respondió con la multiplicación de todas las artes de gobernar (entre las cuales está el arte pedagógico) y todas las instituciones de gobierno; sin embargo, también se acompañó de la necesaria contra-pregunta sobre cómo no ser gobernado "de esa manera, por esas personas, en nombre de esos principios, en vista de determinados objetivos y por medio de determinados procedimientos". Una contra-pregunta que, probablemente, haya oficiado de interpelación primera entre los pueblos colonizados frente al atropello de la conquista; o sea, ya no como contra-interrogante en forma de respuesta a la gubernamentalización, sino como cuestión que ata la actitud crítica a una necesidad de supervivencia.

Por tanto, el "arte de no ser gobernado" como primera definición de la crítica adquiere un matiz diferente entre quienes recurrieron a él como mera contrapartida a un adversario (las artes de gobernar) del que puede desconfiarse, escaparse, al que puede recusarse o transformarse, limitarse o desplazarse, y entre quienes han recurrido a él como forma de resistencia vital y re-existencia (una manera de sobreponerse a una negación de la existencia). Pues, en el marco de la colonización, las comunidades locales se des-cubrieron contrapartes frente al advenimiento de un adversario sin límites en el que estaban obligadas a creer, al que no podían recusar ni transformar, y mucho menos limitar, desplazar o escapar de él. En suma, las 'artes de no ser gobernado' en un contexto semejante adquirió dimensiones estratégicas inimaginables que podían llegar a ir desde mensajes conspirativos ocultos en cabellos trenzados a sueños musculares de rebelión que de vez en cuando se cobraban la vida de un colonizador.

Frente al poder colonial de nuestra época que toma forma en la razón de evaluar, ¿qué matices toma la (actitud) crítica como arte de no ser gobernado? ¿Podremos hablar de un arte de no ser evaluado como manera de limitar, desplazar y escapar del poder de la razón evaluadora? Sabiendo que este poder gusta de transformarse (y mejorarse) toda vez que le sea posible, ¿adónde apuntaría la transformación en este arte? La evocación de cierta continuidad del poder colonial en la razón evaluadora nos da también otra característica desterritorializada que hace a su marco fundamental: una obliga- 
ción de creencia, una reducción de la desconfianza al mínimo posible, un antagonismo con lo que se le oponga, una simulación de sus límites, un planteo de inevitabilidad en su presencia y de imposibilidad de escape. Algo de esto puede llegar a leerse retrospectivamente también, e incluso desnudando sus relaciones íntimas con la ilustración, cuando Foucault $(2018,58-59)$ comenta que se intentaba reconocer en la Aufklärung y en todo ese periodo del siglo $\mathrm{XVI}$ al siglo XVII, que le sirve de referencia, "la línea pendiente más marcada de la razón occidental, en tanto que la política a la que ella estaba ligada era objeto de un examen receloso", lo que insinúa, igualmente, que el periodo colonial señalado no queda exento de una lógica examinadora recelosa funcionando en el corazón de la razón (política) occidental.

Frente a ese panorama, quizás aporte retomar la actitud crítica en sus puntos de anclaje histórico o en la genealogía de la crítica que conjetura Foucault (2018) a partir de la relación con la escritura (en el rechazo al magisterio eclesiástico que establecía su mediación), la relación con la ley (en la no aceptación de leyes y en el establecimiento de los límites del derecho) y la relación con la autoridad (en la no aceptación como verdadero lo que una autoridad establece). La crítica se multiplica, así, en formas de desacato al magisterio, a la ley y a la autoridad; dicho de otro modo, aparece como movimientos que trazan una interrogación sobre los discursos y los efectos del poder. Esto es lo que la instala como un "arte de la inservidumbre voluntaria" y de la "indocilidad reflexiva" (Foucault 2018, 52) al tiempo que cada uno de sus gestos implica alguna desujeción, enseña una inconformidad, construye comunidad y alimentan un combate. Respecto de este último, Foucault $(2018,53)$ señala que el combate suele desdoblarse en dos oponentes complementarios: por un lado, una autoridad, una tradición o un abuso de poder, y, por otro, "una inercia, una ceguera, una ilusión, una cobardía".

No obstante, como advertimos anteriormente, en el planteo foucaultiano late una vena kantiana que termina por hacer desembocar su genealogía en la Aufklärung y reducir a ella la (actitud) crítica con todo lo que eso implica (entre otras cuestiones, privar de infancia a la crítica, ya que esta podría estar solo en manos de "mayores de edad" que hacen "buen uso" de su razón). Quizá sea porque las veredas parisinas de aquel entonces, por las que probablemente se haya paseado el autor de la Historia de la sexualidad, se encontraban desprovistas de esas sillas igualitarias que Roberto Arlt (1994) apellidaba "conventilleras" y en donde hasta un exbarrendero, pasando por la vieja y el peón municipal, podían hacer filosofía barata. Será por eso que Noé Jitrik (2006) da en el clavo cuando dice que, en la tradición filosófica de la modernidad, la crítica tiene una formulación "enceguecedora". Frente a ello, Jitrik $(2006,18)$ planta una genealogía de la (actitud) crítica y le da un triple alcance:

-heurístico: a partir de respaldos sociales y filosóficos "intenta saber "cómo son realmente las cosas' o 'qué se oculta en las declaraciones'”;

-ético: al sacudir la inmovilidad de lo fáctico o el peso de las afirmaciones, fuerza a reconsiderar su pretendido dominio e intenta introducir una modifica- 
ción en el entendimiento acerca de ellas o dirime un combate -lo cual denota que a su ejercicio no le basta "con dejar que la recorran las diversas savias que la alimentan"-;

-político: al ejercerse en el orden de las simples relaciones sociales, tanto su aspecto de articulación como su aspecto de transformación constituyen su politicidad.

A ello se le suma un aspecto huidizo que hace del valor un mero adjetivo en una mala casualidad fugaz y que desdibuja cualquier sustantividad posible en el orden de una tasación. Pues así la actitud crítica convoca por igual a la sensibilidad y la inteligencia, y en ello radica la creatividad de su lectura. En cierta forma, se trata también de la conjunción de lo que Arlt $(1994,92)$ llamaba "el placer de vagabundear" y la "terrible sinceridad", ya que:

para vagar hay que estar por completo despojado de prejuicios y luego ser un poquitín escéptico (...) como esos perros que tienen mirada de hambre y que cuando los llaman menean la cola, pero en vez de acercarse, se alejan, poniendo entre su cuerpo y la humanidad, una respetable distancia.

Y, casi como una definición local de la parresia, la terrible sinceridad reclama interrogarse siempre (aun en el peor minuto de la vida) y sincerarse con todos y consigo "Aunque se rompa el alma contra el obstáculo" (Arlt 1994, 139), aunque depare el perjuicio, la soledad, el aislamiento y la sangre, aunque la equivocación acontezca en el preciso momento en que una fuerza misteriosa lo disponga porque esa es la base y, sobre esa cuerda floja o tensa, cruzamos el abismo de la vida. Sin descuidar los sismos y cataclismos que alimentan el pensamiento que Glissant $(2019,67)$ llama del temblor y que, vinculando sensibilidades e intuiciones, nos lleva a directa y sinuosamente a lo inextricable en que "hay toda la fragilidad que suele reforzar un sistema errático" y en que "ni el cuerpo ni el espíritu se desgreñan o pierden el hilo de la trama".

Un pensamiento tentado (muchas veces de risa) por intuiciones, se asemeja a la chance de entender la crítica también como un gesto narrativo. Es lo que Noé Jitrik (1995) convida en una conferencia de mediados de los años 90, dictada en la Facultad de Humanidades de la Universidad Nacional de Mar del Plata, en la cual señala que la crítica involucra una trama de relaciones complicadas con un problema en la que busca afirmarse; y, del abanico de relaciones posibles e imposibles, caracteriza tres tipos:

-una relación erótica: cuando se pretende desnudar el problema o fusionarse con él; 
-una relación medicinal: cuando se quiere mejorar aquello que causa el problema;

-una relación infantil: cuando se quiere desmontar el problema para ver cómo son sus mecanismos (como cuando en la niñez se desarman los juguetes para ver qué tienen adentro). Jitrik (1995) agrega aquí que, contrariamente a lo que podría pensarse, no se trata de un estadio de la crítica, sino de un modo de proceder, de una actitud.

De ese modo, la crítica se ocupa de un problema, se involucra con él tramando una relación compleja en la que busca afirmarse (incluso en la negación) $y$, en lo que refiere a nuestra cita, podemos ver históricamente que la relación de la crítica con la razón de evaluar ha sido médica, en el sentido en que siempre se ha querido mejorar lo que en ella causaba el problema; y erótica, en el sentido último de fusionarse con el problema hasta perderse en él. Frente a ello, la (actitud) crítica por la que optamos evidencia su relación con la infancia y también el primer sentido de la relación erótica con un plus de histeria; o sea que apunta a la desnudez del problema, pero no para unirse con él, sino para contemplarlo con la mirada de un peligroso can hambriento que pareciera acercarse y no hace más que alejarse sigilosamente.

Tampoco faltan quienes, con una importante inclinación paranoica, suelen considerar a la crítica como perseguidora o, si se la percibe muy fogosa, "reductora". O también quienes la aceptan con un suspiro de condescendencia al considerarla, en última instancia, servicial o re-duplicadora de aquello mismo que intenta desnudar, mejorar o descomponer. Sin embargo, otro sentido de la crítica se cocina en la larga dedicación de Jitrik (1995) a este asunto, sobre todo cuando comenta que se ha pasado la vida tratando de decir lo que "no" es la crítica, un gesto que lo emparenta a Kusch (2007) en su exploración titulada La negación en el pensamiento popular y a un enfático David Viñas cuando en una ruda ocasión televisiva sostuvo que la discrepancia, como práctica de la negatividad, era su un punto de partida, porque decir "no" para Viñas era empezar a pensar. Luego de cortar varios puentes, Jitrik (1995) dinamita quizá el más conectado con la tradición moderna occidental y dice que la crítica no es un juicio de calidad o de falta de calidad, lo que implica -abriéndose totalmente del paradigma kantiano- que tampoco es un juicio de valor. Pues, en contra de Kant, no ve en qué descansa ni dónde se verifica la existencia de esa facultad del espíritu llamada "juicio", es decir, no siente como verdadera esa vertiente que hace de la crítica una calificación o un juicio.

No se trata de un enredo en un trunco esquema hegeliano; más bien de algo que la actitud crítica carga en sí misma: irritaciones, agitaciones, temblores, situaciones socialmente peligrosas o, como mínimo, dificultosas, aunque conducen a cierta reflexión entre la potencia del narrar y la impotencia del explicar. Una suerte de quitarle capas a la cebolla, a riesgo de quedarse sin nada, ensayando caminos de entrada y salida al tiempo que se rompe un esquema de inmovilidad. Entonces, con la paciencia del albañil que va erigiendo andamiajes de sol a sol sin dejar de buscar la sombra, se van habilitando abertu- 
ras que permiten el juego del gesto narrativo y convocan a otros gestos: una ampliación contingente motivada y alimentada por un inconsciente que le va dando forma (a veces escrita, a veces inscrita) y que pide una lectura sin prejuicios en la que el asombro no sea un privilegio. Lo cual, adicionalmente, hunde sus raíces en las enseñanzas populares, puesto que no niega el peso del "a primera vista", anunciante que "de un vistazo inicial igualmente se podría abarcar buena parte de los problemas" y que podría ahorrarnos de "andar por el mundo con la imposición de tener que observar con más hondura que la que ofrecerían esas primeras vistas" (González 2004, 365).

Ello incita a una lectura despenalizadora o, como la llama González (2019, 201), "sintomática", que camina sobre la sospecha de lo que se quiebra en la literalidad de un problema, en su plano no explicitado y que obra como tácito; o late y pugna por decirse hasta que una libertad que lo despenaliza le hace "perder el sistema punitivo que él mismo inventó para no obligarse a decir la verdad". Por ende, se avizora una relación de parentesco entre lectura y crítica, así como entre problema y texto, lo que nos permite percibir de otro modo la noción de crítica como restitución de una idea vinculada a un texto-problema, en razón de que "los textos son palimpsestos dormidos de otras voces de la historia que a veces (...) somete a un tropiezo inquisitorial donde la memoria se deshace o se ritualiza" (González 2018, 122). Lo anterior, como puede notarse, no supone adaptar la crítica a parámetros de lectura masiva para ganar audibilidad social (teniendo que, indefectiblemente, moderar su fuerza de ruptura y dislocación) ni mucho menos satisfacer la demanda de "instantánea legibilidad" que persiguen los mercados de signos y que nunca desarma ni subvierte las reglas de formulación y comprensión diagramada por la lógica de la audiencia.

Tampoco se trata de una oposición a una escucha sin más; es decir, "un escuchar carente de aditamentos y ropajes (...) que queda retenido en la memoria boba, a disposición del momento terrible en que vayamos a interrogar lo banalmente sucedido como indicio de verdades abismales" (González 2004, 365-366). Se trata de una forma de resistir al requerimiento divulgativo de tener que explicar sentidos o enviar "todo lenguaje a una prueba de inteligibilidad proporcionada por los medios de comunicación" (González 1993, 35). Prueba, examen o evaluación que no puede pasarse sin dejar intacto el léxico del "estado de cosas" y sin limar toda aspereza y disonancia que singularizan la crítica en medio de la creciente estandarización. Asperezas de tono, disonancias de lenguaje, rugosidades de vocabulario o lenguajes desafinados, que pueden contradecir -con sus irregularidades- las tendencias homogeneizadoras de la lógica mercantil de la audiencia (y de la razón evaluadora). Si el mercado aspira a la transparencia y la simpleza de signos que deben ser velozmente consumidos, la crítica burla ese artificio cuando planta una demora y no se entrega al desciframiento inmediato, cuando cuida la extrañeza del enigma allí donde radica su potencia de alteridad. 


\section{Arte de no ser evaluado y encarnaciones de la crítica (a manera de conclusión, quizás)}

Quiénes somos

qué pasa

qué extraña historia es esta

por qué la soportamos

si es a costa nuestra

por qué nos soportamos

por qué hacemos el juego.

Idea Vilariño $(2016,54)$.

Cualquiera podría coincidir, en una afirmación más o menos veloz, que Frantz Fanon, Rodolfo Walsh o Antonio Gramsci encarnan en el imaginario colectivo figuras innegables de la crítica o de lo que podría pensarse como 'intelectual crítico'. Sin embargo, en Jorge Bonino puede encontrarse otra figura más enigmática o misteriosa, tal vez una esfinge de la actitud crítica, por su deseo de hacer una crítica del mundo "sin ningún punto de vista". Motivo por el cual, sin haber estudiado teatro y sin pretender realizar una obra, se plantea hacer una escenificación con un lenguaje inventado por él, un lenguaje inexistente que no se entienda, pero que junte gente por una noche y que, durante ese rato, la crítica del mundo ajena a los puntos de vista se concrete de manera tal que "la gente no pudiera aferrarse a ninguna cosa" (en Kamenszain 2014,23 ) y quedara unida por la crítica. Y, si llegaba a decir algo que sonaba inteligible, en el fondo no quería decir nada o se trataba de un juego en el que, cuando parecía llegarse a una conclusión, una ambigüedad radical la frustraba. En palabras de Bonino:

El clima que se creaba era el de dar la sensación de que siempre había que empezar todo de nuevo, por eso empezábamos aprendiendo las letras. El público repetía: a, e, i, o, u. (...) De golpe a mí me daba un desmayo mientras decía: "todos los planes que estamos haciendo están resultando FANTÁSTICOS..." (en Kamenszain 2014, 24).

Hay quienes dicen que halló el grado cero del sentido, aunque también se trate de alguien que hizo de la parodia una enseñanza y de la enseñanza una parodia. Como cuando, durante ese rato en el que intentaba hacer una crítica del mundo, se ubicaba junto a la gente en una posición de infancia en la que nuevamente acontecía la enseñanza del habla y la escritura unida al dibujo, al canto, al baile; en otras palabras, a "algo que pueden hacer todos y no solo algunos" (en Kamenszain 2014, 34). Por eso le gustaba estar cerca de un pizarrón inmenso que le permitía "dibujar un árbol y después acostarse debajo 
de él, o dibujar una ventana y ponerse a mirar por ella" (en Kamenszain 2014,40 ), de ahí que a su enseñanza no le haya resultado complicado el salto de la universidad a la escuela o al jardín de infancias. Aunque es necesaria la aclaración de que, bajo la dictadura de Onganía, Bonino firma un petitorio en contra de las intervenciones de la policía en la universidad y este será el motivo por el cual se trunca su docencia universitaria en la Facultad de Arquitectura:

me echaron de la facultad por firmar un papel de oposición a que hubiera policías en las aulas; en realidad, creo que no interpretaron bien mi propuesta: yo solicitaba que en el caso de que fuera necesario que los agentes anduvieran por ahí, lo hicieran uniformados, pero no convencionalmente, sino como arlequines o payasos. Esta aclaración la escribí al pie de la solicitada que firmamos un grupo grande de personas que trabajábamos en la facultad, pero finalmente me echaron sólo a mí: atribuyo esto a una falta de sensibilidad y creatividad de los servicios de inteligencia (en Casarin 2014, 71).

El redactor, escultor e ilustrador, Jorge Pistocchi $(2014,13)$ relata que con solo contemplar a Bonino ya se recibía su primera lección "que las palabras son un medio pobre de comunicación, que nos hemos olvidado de nuestro cuerpo y que nuestra cara es cada día menos expresiva". Entonces, mientras cualquiera podía detenerse en los pensamientos que semejante enseñanza artística suscitaba, Bonino ya estaba siendo el maestro capaz de transfor- 3. Un 17 de abril, pero de 1990, marse en infinitos personajes que aclaran ciertas dudas (sin hacerlo jamás o, Jorge Bonino realizó su último mejor, sin perder nunca ese estado de infancia que irradiaba a su alrededor y que a tanta gente molestaba al punto de resultarle insoportable). Como solo alguien que se propone una actividad crítica semejante, el llamado "mimo sonoro" logra reír último y reír mejor al tirarse al pozo por no aceptar adueñarse él solo de esa risa dichosa y contagiarla al resto en un gesto de desprendimiento absoluto. Un gesto que subvierte la filosofía occidental al unir, en una misma actuación, al crítico y la risa que causa. ${ }^{3}$ En este preciso sentido (quizá bordeando su grado cero), podría evocarse la memoria de Piglia (2015, 346) cuando permite recordar:

al filósofo Tales que, al caminar ensimismado, mientras observaba el firmamento tratando de captar la verdad oculta del universo, se cayó en un pozo, lo que produjo la risa de una joven campesina que se estaba lavando el acto: un salto único e irrepetible. Luego, una enfermera provinciana comentaría a un amigo que le llamaba desde lejos: "El señor Bonino ha fallecido de un intento de suicidio...". Este fue el gran final de la vida (hecha obra) de quien encarnó una crítica del mundo en un lenguaje inexistente. Entre sus enseñanzas, y las huellas que dejó en el planisferio, quedó un pequeño registro fílmico que en su nombre combina las onomatopeyas del asombro y el dolor: ¡Guauch! Allí, todavía pueden verse sus gestualidades eternamente enigmáticas:

https://vimeo.com/31871716. 
pelo en el agua de una fuente. Y muchos han dicho después que hay más filosofía en esa risa jovial que en los profundos pensamientos del filósofo que se fue al fondo de un hoyo por no mirar por dónde caminaba.

\section{Bibliografía}

Agamben, Giorgio. 2018. Karman: breve tratado sobre la acción, la culpa y el gesto. Buenos Aires: Adriana Hidalgo.

Arlt, Roberto. 1994. Aguafuertes porteñas. Buenos Aires: Losada.

Casarín, Marcelo. 2014. «Bonino, actor de mi propia obra». En Aclara ciertas dudas. Entrevistas a Jorge Bonino, editado por Marcelo Casarin et. al., 49-85. Córdoba: Caballo Negro.

Cioran, Emil. 2015 [1964]. La caída en el tiempo. Barcelona: Tusquets.

Foucault, Michel. 2000. Los anormales. Curso en el Collège de France (1974-1975). Buenos Aires: Fondo de Cultura Económica.

Foucault, Michel. 2018. ¿Qué es la crítica? seguido de La cultura de sí. Buenos Aires: Siglo XXI.

Frigerio, Graciela. 2011. A la sombra de PISA: versión preliminar y descartable. Inédito.

Giuliano, Facundo. 2017. Rebeliones éticas, palabras comunes. Conversaciones (filosóficas, políticas, educativas) con Judith Butler, Raúl Fornet-Betancourt, Walter Mignolo, Jacques Rancière, Slavoj Žižek. Buenos Aires: Miño y Dávila.

Giuliano, Facundo. 2018. «En torno a lo imposible: una aventura común, entre psicoanálisis y educación, con Jorge Alemán». Estudios de Filosofía Práctica e Historia de las ideas, (20)17, 1-35. 
Glissant, Édouard. 2019. Filosofía de la relación: poesía en extensión. Buenos Aires: Miluno.

González, Horacio. 1993. «Teoría con nombre propio». El ojo mocho, (3), 35.

González, Horacio. 2004. Filosofía de la conspiración: marxistas, peronistas y carbonarios. Buenos Aires: Colihue.

González, Horacio. 2018. Saberes de pasillo: universidad y conocimiento libre, compilado por Juan Laxagueborde. Buenos Aires: Paradiso.

González, Horacio. 2019. Borges. Los pueblos bárbaros. Buenos Aires: Colihue.

Hernández, José. 2009. Martín Fierro. Buenos Aires: RTM.

Jitrik, Noé. 1995. Un resumen sobre la crítica. (Conferencia pronunciada en la Facultad de Humanidades de la Universidad Nacional de Mar del Plata). Inédito.

Jitrik, Noé. 2006. Productividad de la crítica. La biblioteca, (4-5), 16-25.

Kamenszain, Tamara. 2014. «El espectáculo no puede detenerse». En Aclara ciertas dudas. Entrevistas a Jorge Bonino, editado por Marcelo Casarin et. al., 19-41. Córdoba: Caballo Negro.

Kusch, Rodolfo. 2007. Obras completas: v. 2. Rosario: Fundación Ross.

Laxagueborde, Juan. 2018. «Prólogo. Quedarse libre». En Saberes de pasillo: universidad y conocimiento libre, compilado por Juan Laxagueborde, 7-23. Buenos Aires: Paradiso.

Martínez Estrada, Ezequiel. 2013. Mensajes. Buenos Aires: Interzona/Ediuns. Nancy, Jean-Luc. 2009. La verdad de la democracia. Buenos Aires: Amorrortu.

Piglia, Ricardo. 2015. Los diarios de Emilio Renzi: años de formación. Barcelona: Anagrama. 
Pistocchi, Jorge. 2014. «Las máscaras de Bonino». En: Aclara ciertas dudas. Entrevistas a Jorge Bonino, editado por Marcelo Casarin et. al., 11-17. Córdoba: Caballo Negro.

Roth, Philip. 2006. Pastoral americana. Buenos Aires: Debolsillo.

Santoro, Roberto Jorge. 2013. Obra poética completa 1959-1977. Buenos Aires: RyR.

Scalabrini Ortíz, Raúl. 1933. El hombre que está solo y espera. Buenos Aires: Librerías Anaconda.

Schulz, Kathryn. 2015. En defensa del error. Un ensayo sobre el arte de equivocarse. Madrid: Siruela.

Skliar, Carlos. 2003. ¿Y si el otro no estuviera ahí? Notas para una pedagogía (improbable) de la diferencia. Buenos Aires: Miño y Dávila.

Skliar, Carlos. 2011. Lo dicho, lo escrito, lo ignorado. Ensayos mínimos entre educación, filosofía y literatura. Buenos Aires: Miño y Dávila.

Tavares, Gonçalo. 2018. Enciclopedia. Zaragoza: Xordica.

Vilariño, Idea. 2016. En lo más implacable de la noche: antología personal. Buenos Aires: Colihue.

Wilde, Oscar. 2004. Una mujer sin importancia. Buenos Aires: Losada. 